\title{
Pharmacokinetic and Pharmacodynamic Modeling of a Novel Thromboxane Synthetase Inhibitor, DP-1904, in Human
}

\author{
Nian Xin Zheng, Hitoshi Sato, Isao Adachi, Isamu HoRIKoshi \\ Department of Hospital Pharmacy, Toyama Medical and Pharmaceutical University, \\ 2630 Sugitani, Toyama 930-01, Japan
}

\begin{abstract}
Summary
Pharmacokinetic and pharmacodynamic (PK/PD) analyses for a novel thromboxane synthetase inhibitor, DP-1904, were performed to predict its $\mathrm{PK} / \mathrm{PD}$ profiles in human after single and repeated oral administration. The pharmacodynamics of DP-1904 was characterized by serum levels of thromboxane $\mathrm{B}_{2}\left(\mathrm{TXB}_{2}\right)$, a pharmacological marker for thromboxane synthetase inhibition. Based on a quantitative relationship between the plasma DP1904 and serum $\mathrm{TXB}_{2}$ concentrations after single oral dosage, $\mathrm{IC}_{50}$ and $\mathrm{E}_{\max }$ values were estimated to be $0.54 \mathrm{ng} / \mathrm{m} l$ and $94 \%$, respectively. An integrated, simple PK/PD model was developed to simulate the changes in serum $\mathrm{TXB}_{2}$ levels after single oral administration of DP-1904 at various doses, and the simulation curves corresponded well with the observed data. The PK/PD model was then used to predict a pharmacological profile of DP-1904 after repeated oral doses in human; the predicted curves were in relatively good agreement with the observed data. Thus, it is suggested that our $\mathrm{PK} / \mathrm{PD}$ model is feasible and practical for developing optimum dosing regimens of DP-1904 in clinical situations.
\end{abstract}

Key words : DP-1904, Thromboxane synthetase inhibitor, Pharmacokinetics, Pharmacodynamics, Human, STELLA model

\section{Introduction}

Recently, selective thromboxane synthetase inhibitors have been studied and developed for the treatment of asthma and cardiovascular diseases ${ }^{1-4}$. However, there have been only qualitative knowledge on the $\mathrm{PK} / \mathrm{PD}$ relationships of these drugs in human ${ }^{5-8)}$ so far. We have fabricated an integrated mathematical model to predict the pharmacokinetics and pharmacodynamics (PK/PD) of ozagrel, a new thromboxane synthetase inhibitor, in rabbits (manuscript submitted for publication). In this study, therefore, we applied our model to predict the PK/PD profiles of DP-1904 (Fig. 1) in human subjects, in order to provide a rational basis for optimizing the therapeutic regimens of thromboxane synthetase inhibitors. The pharmacodynamic part of our model is based on a scheme (Fig. 2) that $\mathrm{TXB}_{2}$ is synthesized with a zero-order rate constant $\left(\mathrm{R}_{\mathrm{syn}}\right)$ and degraded with a first-order rate constant $\left(\mathrm{k}_{\mathrm{deg}}\right)$, and that $\mathrm{DP}-1904$ inhibits the production of $\mathrm{TXB}_{2}$ by inhibition of $\mathrm{R}_{\mathrm{syn}}$. Thus, the pharmacodynamic model of ozagrel is analogous to those of an anticoagulant drug, warfarin ${ }^{9)}$, a fibrinogen receptor antagonist, $\mathrm{L}-703,014^{10)}$, and an aldose reductase inhibitor, AL $1576^{11)}$.

\section{Subjects and Methods}

Plasma DP-1904 and serum $\mathrm{TXB}_{2}$ concentration data after single and repeated oral administration of DP-1904 in normal human volunteers ${ }^{7,8)}$ were supplied by Daiichi Pharm. Co. (Tokyo, Japan). These 


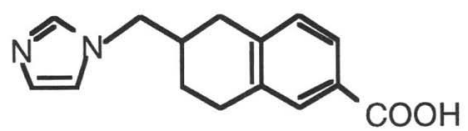

$\bullet \mathrm{HCl} \cdot 1 / 2 \mathrm{H}_{2} \mathrm{O}$

Fig. 1 The chemical structure of DP-1904.

\section{DP-1904}

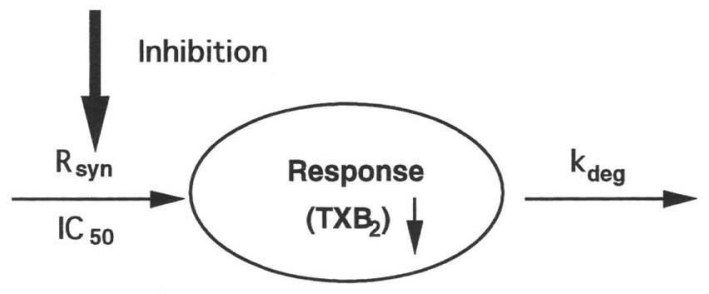

Fig. 2 An illustration of pharmacodynamic indirect response model for DP-1904 characterized by its inhibition of $\mathrm{TXB}_{2}$ synthesis.

data were used for further analyses to estimate the $\mathrm{PK} / \mathrm{PD}$ parameters of the drug in human as described below. All the fitting procedures were conducted on a personal computer (PC-9801DA, NEC, Tokyo, Japan) using a nonlinear least-squares regression analysis, MULTI ${ }^{12)}$, implemented in $\mathrm{S}^{-}$ CALC $^{13)}$.

\section{Pharmacokinetic Analysis}

For single oral administration at several different doses (i.e. 10, 20, 50, 100, 200, and $400 \mathrm{mg}$ ) of DP1904, the plasma concentration data were simultaneously fitted to the following three-exponential equation, assuming linear pharmacokinetics:

$$
\mathrm{C}_{\mathrm{p}}=\mathrm{D} \cdot\left\{\mathrm{A} \cdot \mathrm{e}^{-\alpha\left(\mathrm{t}-\mathrm{t}_{0}\right)}+\mathrm{B} \cdot \mathrm{e}^{-\beta \cdot\left(\mathrm{t}-\mathrm{t}_{0}\right)}-(\mathrm{A}+\mathrm{B}) \cdot \mathrm{e}^{-\gamma \cdot\left(\mathrm{t}-\mathrm{t}_{0}\right)}\right\}
$$

where $\mathrm{Cp}$ is the plasma concentration $(\mu \mathrm{g} / \mathrm{m} l)$ of DP-1904; $\mathrm{D}$ is the dose administered $(\mu \mathrm{g}) ; \alpha$, $\beta$, and $\gamma$ represent the hybrid constants for the slopes of plasma concentration-time curves; A and B are the intercepts of monoexponential lines with the slopes of $\alpha$ and $\beta$, respectively; $t$ is the time after dosing; and $t_{0}$ is the lag time for drug absorption. The above-obtained parameters (i.e., $\mathrm{A}, \alpha, \mathrm{B}, \beta, \gamma$, and $\mathrm{t}_{0}$ ) were used to predict drug concentrations in plasma after repeated oral dosing, according to the following equation:

$$
\begin{aligned}
C_{p}= & D \cdot\left\{A \cdot \frac{1-e^{-n \cdot \alpha \cdot \tau}}{1-e^{-\alpha \cdot \tau}} \cdot e^{-\alpha \cdot\left(t^{\prime}-t_{0}\right)}\right\}+\left\{B \cdot \frac{1-e^{-n \cdot \beta \cdot \tau}}{1-e^{-\beta \cdot \tau}} \cdot e^{-\beta \cdot\left(t^{\prime}-t_{0}\right)}\right\} \\
& -\left\{(A+B) \cdot \frac{1-e^{-n \cdot \gamma \cdot \tau}}{1-e^{-\gamma \cdot \tau}} \cdot e^{-\gamma \cdot\left(t^{\prime}-t_{0}\right)}\right\}
\end{aligned}
$$

where $\tau$ is the dosing interval, $\mathrm{n}$ is the number of doses given, and $\mathrm{t}$ ' is the time after the $\mathrm{n}$-th dosing.

\section{Pharmacodynamic Analysis}

Serum $\mathrm{TXB}_{2}$ levels were converted to percentage inhibition of $\mathrm{TXB}_{2}$ as follows:

$$
\mathrm{E}\left(\mathrm{TXB}_{2}\right)=\frac{\mathrm{TXB}_{2}^{0}-\mathrm{TXB}_{2}}{\mathrm{TXB}_{2}^{0}} \times 100
$$

where $\mathrm{TXB}_{2}$ denotes the serum $\mathrm{TXB}_{2}$ level at a designated time after dosing, and $\mathrm{TXB}_{2}^{0}$ is the premedicated level of $\mathrm{TXB}_{2}$. The relationship between the plasma DP-1904 concentration (Cp) and pharmacological effect of $\mathrm{DP}-1904, \mathrm{E}\left(\mathrm{TXB}_{2}\right)$, was fitted to the following equation: 


$$
\mathrm{E}\left(\mathrm{TXB}_{2}\right)=\frac{\mathrm{E}_{\max } \cdot \mathrm{C}_{\mathrm{p}}}{\mathrm{IC}_{50}\left(\mathrm{TXB}_{2}\right)+\mathrm{C}_{\mathrm{p}}}
$$

where $\mathrm{IC}_{50}\left(\mathrm{TXB}_{2}\right)$ is the drug concentration which yields $50 \%$ of the maximum $\mathrm{TXB}_{2}$ inhibition; $\mathrm{E}_{\max }$ is the maximum $\mathrm{TXB}_{2}$ inhibitory effect. The estimated $\mathrm{E}_{\max }$ and $\mathrm{IC}_{50}\left(\mathrm{TXB}_{2}\right)$ after oral dosage were used to simulate the $\mathrm{PK} / \mathrm{PD}$ profiles after oral single doses, and further to predict them after oral repeated dose.

\section{Integrated PK/PD Simulation}

The PK/PD model for ozagrel developed in rabbits (submitted for publication) was employed to predict the PK/PD profiles of DP-1904 in human. The simulation was conducted on a Macintosh computer (Centris 660AV) with a mathematical co-processor using a program of STELLA (High Performance System, Inc., USA). The diagram of the STELLA model is shown in Fig. 3. STELLA program is a tool for model development and its numerical solution that allows us to easily and rapidly simulate complex kinetic processes. Due to its efficient capability, STELLA has been utilized in recent pharmacokinetic papers. ${ }^{14,15)}$ As shown in Fig. 3, submodel A represents the pharmacokinetic part for oral dosing and submodel B corresponds to the pharmacodynamic part. This model enables one to easily change the dose and dosing interval for predicting the $\mathrm{PK} / \mathrm{PD}$ of the drug after single or repeated oral dosing. The pharmacodynamic part of the model (submodel B) is based on a scheme that $\mathrm{TXB}_{2}$ is synthesized with a zero-order rate constant $\left(\mathrm{R}_{\mathrm{syn}}\right)$ and degraded with a first-order rate constant $\left(\mathrm{k}_{\mathrm{deg}}\right)$, and that $\mathrm{DP}-1904$ inhibits the production of $\mathrm{TXB}_{2}$ by inhibition of $\mathrm{R}_{\mathrm{syn}}$. Therefore, the effect of $\mathrm{DP}-1904$ is modeled as an inhibitory factor of $\mathrm{R}_{\mathrm{syn}}$. Thus, changes in serum $\mathrm{TXB}_{2}$ can be expressed as:

$$
\frac{\mathrm{dTXB}_{2}}{\mathrm{dt}}=\mathrm{R}_{\mathrm{syn}}-\mathrm{k}_{\mathrm{deg}} \cdot \mathrm{TXB}_{2}=\mathrm{R}_{\mathrm{syn}}^{0}\left(1-\frac{\mathrm{E}_{\mathrm{max}} \cdot \mathrm{C}_{\mathrm{p}}}{\mathrm{IC}_{50}+\mathrm{C}_{\mathrm{p}}}\right)-\mathrm{k}_{\mathrm{deg}} \cdot \mathrm{TXB}_{2}
$$

where $\mathrm{R}_{\mathrm{syn}}^{0}$ represents $\mathrm{TXB}_{2}$ synthesis rate before dosing and can be expressed as:

$$
\mathrm{R}_{\mathrm{syn}}^{0}=\mathrm{k}_{\mathrm{deg}} \cdot \mathrm{TXB}_{2}^{0}
$$

where $k_{\text {deg }}$ is the first-order degradation rate constant of serum $\mathrm{TXB}_{2}$ and $\mathrm{TXB}_{2}^{0}$ is the basal level of serum $\mathrm{TXB}_{2}$ before dosing. Equation 6 was derived from Eq. 5, assuming a steady state before dosing (i.e., $\mathrm{dTXB}_{2} / \mathrm{dt}=0$ and $\mathrm{C}_{\mathrm{p}}=0$ ). Since a marked reduction of serum $\mathrm{TXB}_{2}$ was exhibited after the administration of DP-1904 even at lower doses, the value of $\mathrm{k}_{\mathrm{deg}}$ was assigned to be $6.0 \mathrm{hr}^{-1}$, a value large enough to explain the rapid fall of serum $\mathrm{TXB}_{2}$.

\section{Results}

The plasma concentration vs. time curves of $\mathrm{DP}-1904$ at various oral doses were fitted simultaneously to Eq. (1), and the pharmacokinetic parameters obtained by the Simplex method are; $A=7.74 \times 10^{-7}$ $\left(\mathrm{m} l^{-1}\right), \alpha=0.232\left(\mathrm{hr}^{-1}\right), \mathrm{B}=3.33 \times 10^{-5}\left(\mathrm{~m} l^{-1}\right), \beta=1.21\left(\mathrm{hr}^{-1}\right), \gamma=11.2\left(\mathrm{hr}^{-1}\right)$, and $\mathrm{t}_{0}=0.445(\mathrm{hr})$. The calculated curves corresponded well with the observed data, as shown in Fig. 4.

The relationships between pharmacological effect $(\mathrm{E})$ and plasma concentrations $\left(\mathrm{C}_{\mathrm{p}}\right)$ of $\mathrm{DP}-1904$ after oral dosages were fitted individually to Eq. (3) (a typical result shown in Fig. 5), and the obtained pharmacodynamic parameters are listed in Table $\mathbf{I}$. The $\mathrm{IC}_{50}$ and $\mathrm{E}_{\max }$ values were estimated to be $0.54 \pm 0.09 \mathrm{ng} / \mathrm{ml}$ and $94 \pm 1 \%$ (mean \pm S.E.M.; $\mathrm{n}=6$ ), respectively. 
A
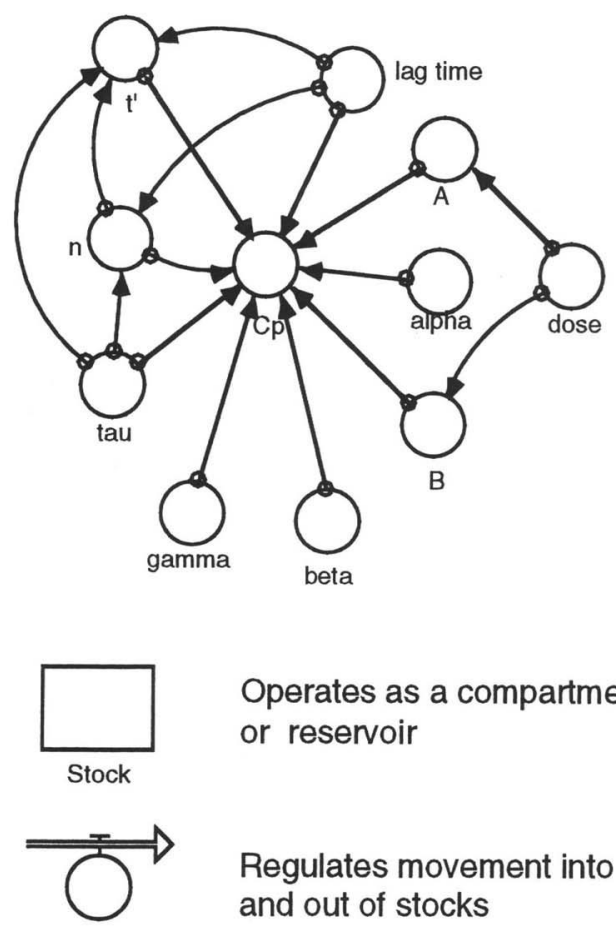

Flow regulator

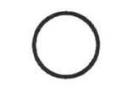

Converter
Operates as a compartment or resenvoir

Regulates movement into and out of stocks Modifies flow regulator or
other converters. Allows
calculation of parameters
using "stock" values

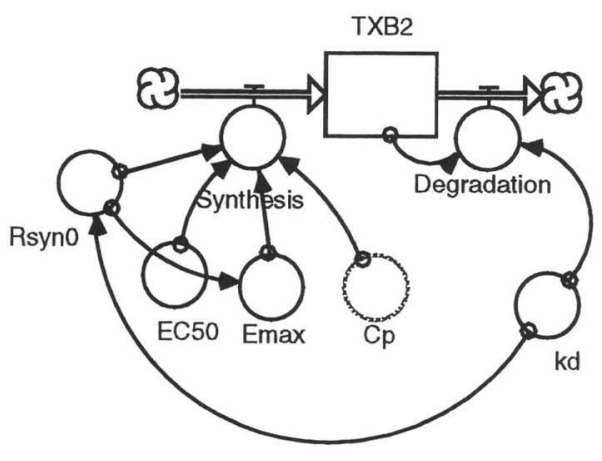

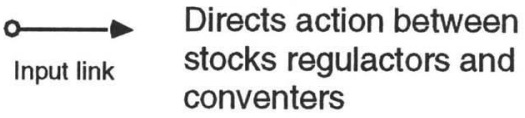

$Q$

Cloud

Infinite reservoir

Cin

Ghost Contains the same value
of another converter

Fig. 3 A diagram of STELLA model to simulate the PK/PD of DP-1904 in normal human volunteers after single or multiple repeated oral dosing. Panels A and B illustrate the submodels for pharmacokinetics and pharmacodynamics, respectively. In the lower part, the definition of each model symbol is described.

The above-obtained PK/PD parameters were then used to simulate the pharmacological profiles of DP-1904 at various oral doses, using the STELLA model shown in Fig. 3, Fig. 6 illustrates the observed and simulated concentrations of serum $\mathrm{TXB}_{2}$, which are in general agreement with each other. This suggests feasibility of the method of $\mathrm{PK} / \mathrm{PD}$ parameter estimation.

Moreover, the PK/PD profiles of DP-1904 after repeated oral dosing (200 mg, twice a day for two days and $400 \mathrm{mg}$, once a day for two days) were predicted using the STELLA model, in which the above-obtained PK/PD parameters are incorporated. As shown in Fig. 7 and Fig. 8, the predicted curves are in good correspondence with the observed data, indicating the feasibility of our PK/PD model. 


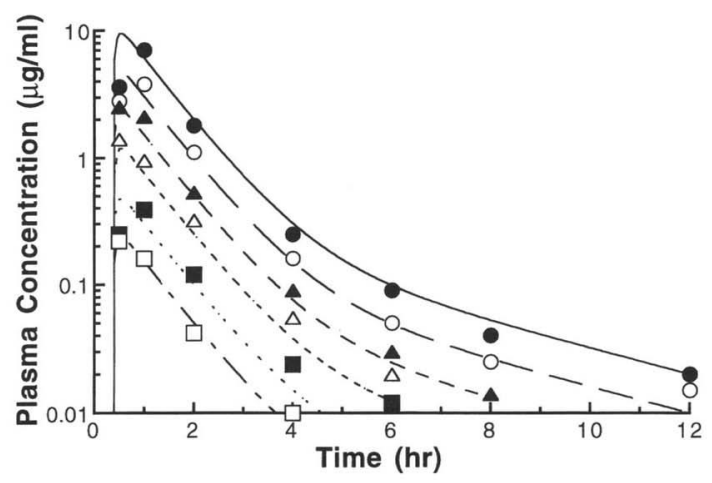

Fig. 4 Plasma concentration profiles of DP-1904 after oral administration at various doses. Lines show the computer-generated fitting curves according to Eq. (1). (O) $400 \mathrm{mg}$, (O) $200 \mathrm{mg}$,

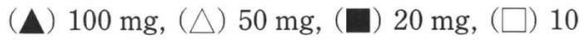
mg.

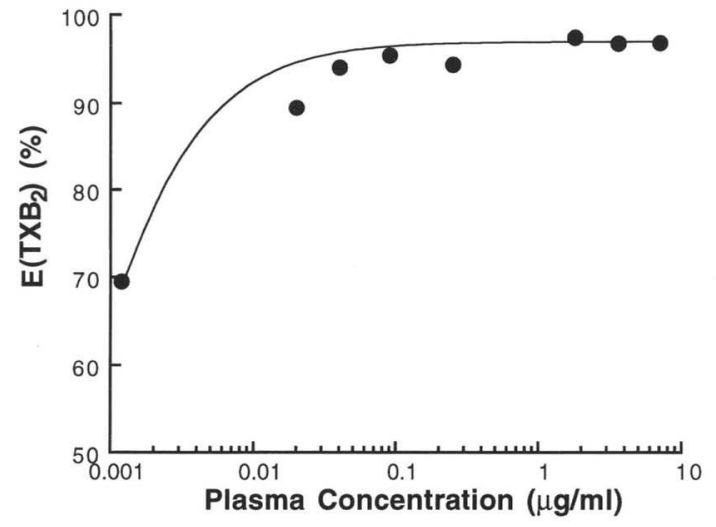

Fig. 5 A typical relationship between serum level of $\mathrm{TXB}_{2}$ (E) vs. plasma concentration of $\mathrm{DP}-$ 1904 (Cp) after oral administration of $400 \mathrm{mg}$ DP-1904. The line shows the fitting curve according to Eq. (4).

Table I Pharmacodynamic parameters of DP-1904 obtained from plasma DP-1904 and serum $\mathrm{TXB}_{2}$ concentrations after oral doses in human

\begin{tabular}{ccc}
\hline Dose $(\mathrm{mg})$ & $\mathrm{IC}_{50}(\mathrm{ng} / \mathrm{m} l)^{\mathrm{a})}$ & $\mathrm{E}_{\max }(\%)^{\mathrm{a})}$ \\
\hline 10 & 0.45 & 96 \\
20 & 0.67 & 96 \\
50 & 0.58 & 90 \\
100 & 0.90 & 93 \\
200 & 0.26 & 94 \\
400 & 0.40 & 95 \\
Mean +S.E.M. & $0.54 \pm 0.09$ & $94 \pm 1$
\end{tabular}

a) Estimated by a nonlinear least-squares regression, MULTI ${ }^{12}$, implemented in S-CALC ${ }^{13)}$.

\section{Discussion}

Dosage regimens of thromboxane synthetase inhibitors in clinical practice have been based mainly on empirical grounds. However, in order to maximize the efficacy/toxicity ratio of these drugs, therapeutic protocols should be designed based on adequate understanding of their PK/PD in a quantitative and comprehensive manner. Among the four basic models (Models I-IV) recently proposed by Dayneka et al. ${ }^{16}$ ) to describe the pharmacodynamics of drugs with mechanisms producing indirect responses, we have applied the Model I to DP-1904, where the direction of the pharmacological response is inhibition and the factor affected is the input of response control. The estimated $\mathrm{IC}_{50}(0.54 \mathrm{ng} / \mathrm{m} l)$ for DP-1904 in human is lower than that $(11.8 \mathrm{ng} / \mathrm{ml})$ for ozagrel in human ${ }^{17)}$, suggesting that DP-1904 is a potent and long acting thromboxane synthetase inhibitor compared with a marketed drug with the same mechanism of 

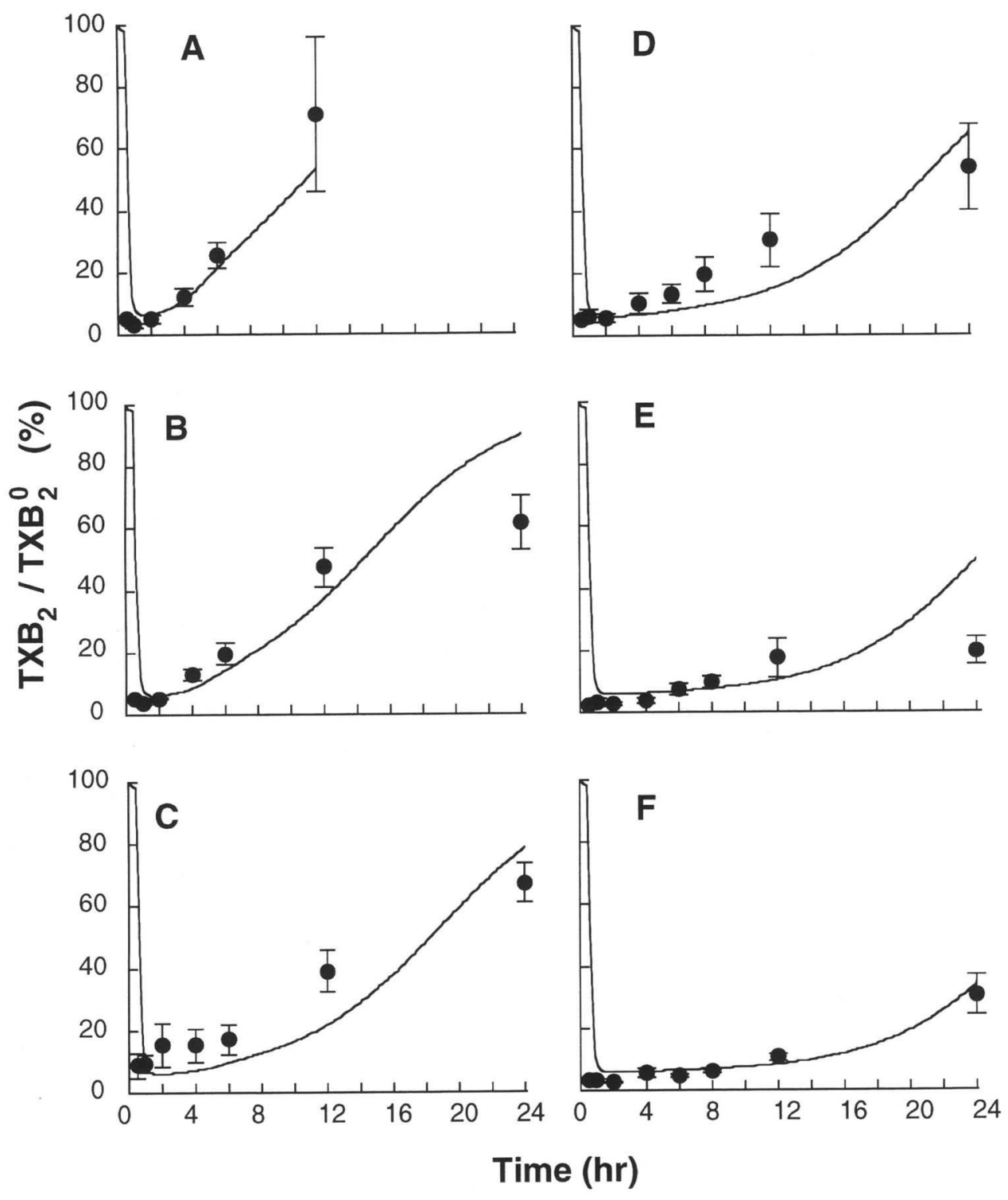

Fig. 6 Serum $\mathrm{TXB}_{2}$ changes after oral administration of DP-1904 in various doses. Lines show the simulated curves using pharmacokinetic parameters (see text) and pharmacodynamic parameters (Table I). Each point and vertical bar represent the mean \pm S.D. $(n=5)$. A; $10 \mathrm{mg}, \mathrm{B} ; 20 \mathrm{mg}, \mathrm{C} ; 50 \mathrm{mg}, \mathrm{D} ; 100 \mathrm{mg}, \mathrm{E} ; 200$ mg, F; 400 mg.

action. The PK/PD model thus developed were in general agreement with the data taken at the wide dose range, as shown in Fig. 6. The exact reason for the moderate inconsistency between the simulated and observed $\mathrm{TXB}_{2}$ values at the middle dose range (i.e., $50-100 \mathrm{mg}$ ) is not known in this study, but there might be another pharmacokinetic and/or pharmacodynamic factor to consider to fully accommodate the pharmacological effect of DP-1904 in human at various doses. Perhaps, the pharmacodynamic bias in the effect-drug concentration relationship (as in a typical example shown in Fig. 5) at 0.001-0.1 

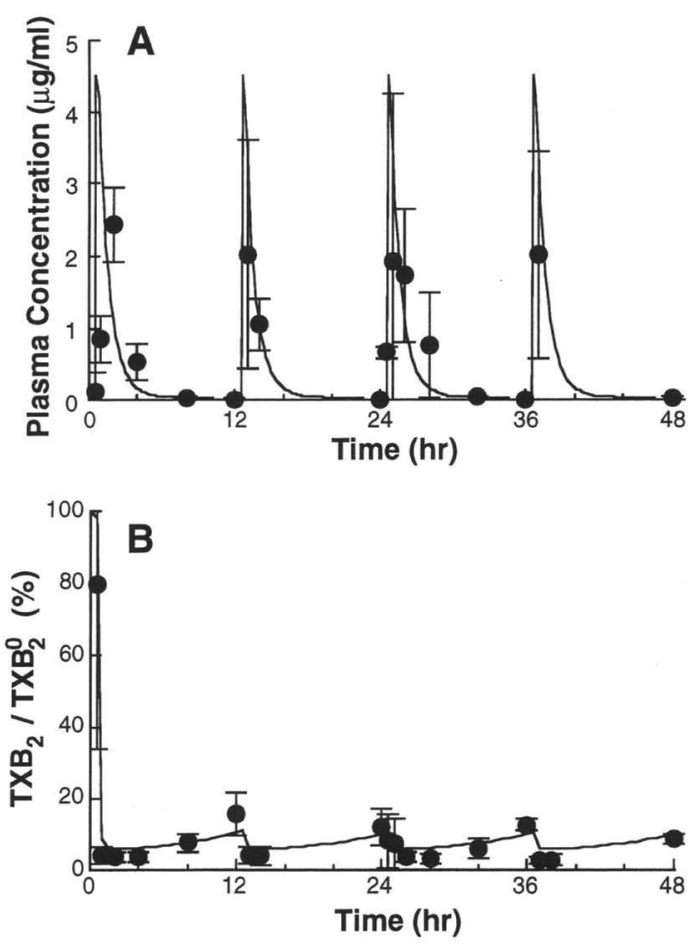

Fig. 7 Changes in plasma DP-1904 (A) and serum $\mathrm{TXB}_{2}$ (B) concentrations after repeated oral administration $(200 \mathrm{mg}$, twice a day for two days). The lines show the computer-generated predicted curves using pharmacokinetic parameters (see text) and pharmacodynamic parameters (Table I). Each point and vertical bar represent the mean \pm S.D. $(n=5)$.
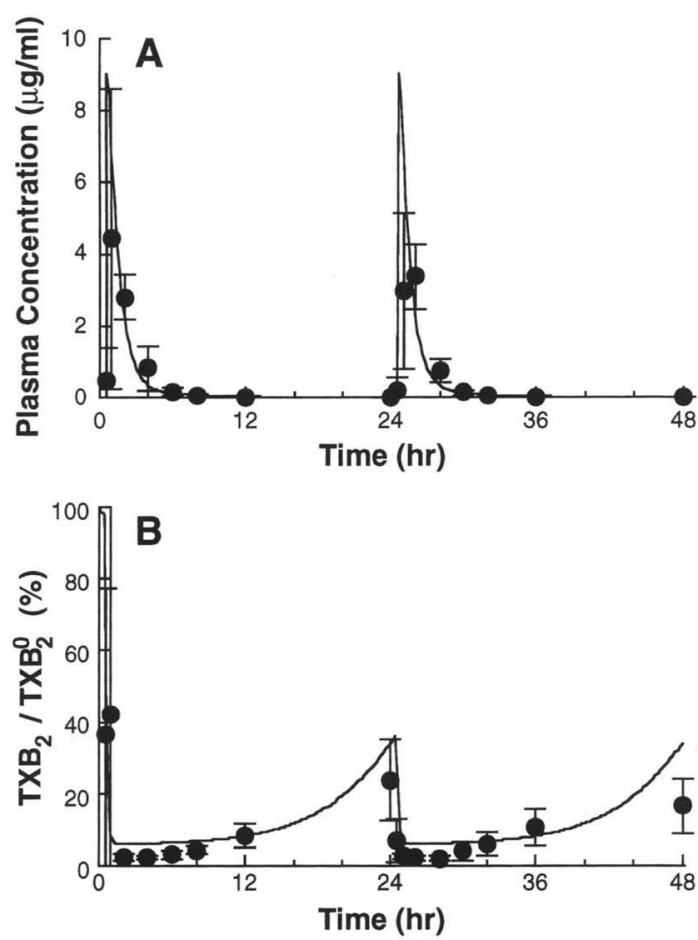

Fig. 8 Changes in plasma DP-1904 (A) and serum $\mathrm{TXB}_{2}$ (B) concentrations after repeated oral administration $(400 \mathrm{mg}$, once a day for two days). The lines show the computer-generated predicted curves using pharmacokinetic parameters (see text) and pharmacodynamic parameters (Table I). Each point and vertical bar represent the mean \pm S.D. $(n=5)$.

$\mu \mathrm{g} / \mathrm{ml}$ may be related to the inconsistency at the middle dose range.

In the present pharmacodynamic model, the pharmacological effect of DP-1904 was modeled as an inhibiting factor of Rsyn; this is because of the fact that the level of $\mathrm{TXB}_{2}$ is the function of the rates of $\mathrm{TXB}_{2}$ synthesis and degradation ${ }^{18)}$, and that DP-1904 inhibits $\mathrm{TXA}_{2}$ synthetase ${ }^{2}$. However, since the interval of blood sampling was not always short enough to accurately calculate the synthesis rate of $\mathrm{TXB}_{2}$ at a specific time point (i.e., the middle of the two sampling times), we first estimated the $\mathrm{IC}_{50}$ value from the plasma DP-1904 concentration vs. serum $\mathrm{TXB}_{2}$ relationship (a typical result shown in Fig. 5) and incorporated this value into the $\mathrm{IC}_{50}$ of $\mathrm{TXA}_{2}$ synthetase inhibition. The feasibility of this procedure was confirmed by our preliminary simulation which showed that the two $\mathrm{IC}_{50}$ values for $\mathrm{E}\left(\mathrm{TXB}_{2}\right)$ and $\mathrm{E}$ $\left(\mathrm{R}_{\text {syn }}\right)\left(=\left(\mathrm{R}_{\text {syn }}^{0}-\mathrm{R}_{\text {syn }}\right) / \mathrm{R}_{\text {syn }}^{0} \times 100\right)$ had a ratio of nearly 1 . This should be explained by the large $\mathrm{k}_{\mathrm{deg}}$ value that made the time-lag between the inhibition of $\mathrm{R}_{\text {syn }}$ and $\mathrm{TXB}_{2}$ negligible. Clearly, the serum $\mathrm{TXB}_{2}$ is a direct pharmacological marker for a $\mathrm{TXA}_{2}$ synthetase inhibitor, and can be easily monitored in clinical settings where one cannot sample blood from patients in frequent times.

In conclusion, a simple mathematical model was assembled for predicting the PK/PD of DP-1904 in 
human after single and repeated oral dosing. The PK/PD model was successfully applied to various doses and multiple dosing of DP-1904, and thus may be useful for developing optimum dosing regimens of the drug in clinical situations. Moreover, the present modeling procedure should be applied to other thromboxane synthetase inhibitors.

Acknowledgments : The authors greatly thank Drs. Hideo Hakusui and Kyuichi Matsubayashi (Daiichi Pharm. Co.) for providing us with plasma DP-1904 and serum $\mathrm{TXB}_{2}$ concentration data obtained from normal human volunteers.

\section{References}

1) Iizuka, K., Akahane, K., Momose, D. and Nakazawa, M.: Highly selective inhibitor of thromboxane synthetase. 1. Imidazole derivatives. J. Med. Chem., 24: 1139-1148 (1981).

2) Kanao, M., Watanabe, Y., Kimura, Y., Saegusa, J., Yamamoto, K., Kanno, H., Kanaya, N., Kubo, H., Ashida, S. and Ishikawa, F.: Thromboxane $\mathrm{A}_{2}$ synthetase inhibitor. 2. Syntheses and activities of tetrahydronaphthalene and indan derivatives. $J$. Med. Chem., 32: 1326-1334 (1989).

3) Makino, S., Miyamoto, T., Takishima, T., Shida, T., Nagano, H., Nakashima, M. and Hanaoka, K.: Utility of $\mathrm{OKY}-046 \cdot \mathrm{HCl} \cdot \mathrm{H}_{2} \mathrm{O}$, a selective thromboxane synthetase inhibitor on adult bronchial asthma. Rinsho Igaku, 6: 2131-2165 (1990).

4) Ohtomo, E., Kutsuzawa, T., Kogure, K., Hirai, S., Goto, F., Terashi. A., Tazaki, Y., Araki, G., Ito, E., Fujishima, M. and Nakashima, M.: Clinical usefulness of OKY-046 on the acute stage of cerebral thrombosis. Rinsho Igaku, 7: 353-388 (1991).

5) Fukushima, M., Kubo, K., Yoshimura, K., Shibamoto, T., Fujimoto, K., Hirai, K., Kobayashi, T., Kusama, S., Komatsu, H., Hamano, S., Ujiie, A., Shimizu, M., Miyagi, M., Morita, K., Mikoshiba, I., Hiraku, S. and Ohki, S.: Phase I study of OKY-046, a selective thromboxane synthetase inhibitor-study on one-shot and continuous intravenous administrations. Yakuri To Chiryo, 14: 277-307 (1986).

6) Fukushima, M., Kubo, K., Yoshimura, K., Shibamoto, T., Yazaki, K., Kobayashi, T., Kanda, K., Kusama, S., Komatsu, H., Shimizu, M., Miyagi, M., Morita, K., Mikoshiba, I., Saito, H., Hiraku, S. and Ohki, S.: Phase I study of OKY-046, a selective thromboxane synthetase inhibitor-study on single and repeated oral administrations. Kiso To Rinsyo, 24: 197-219 (1990).

7) Tanaka, M., Ono, K., Takegoshi, T., Shiozawa, T., Suzuki, T., Nii, S. and Shibata, H.: The pharmacokinetics and pharmacodynamics of a new thromboxane synthetase inhibitor, 6-(1-Imidazolylmethyl)-5,6,7,8-tetrahydronaphthalene-2-carboxylic acid (DP-1904), in man after single oral administration. J. Pharm. Pharmacol., 41: 680-684 (1989).

8) Tanaka, M., Ono, K., Takegoshi, T., Shiozawa, T., Suzuki, T., Nii, S. and Shibata, H.: The pharmacokinetics and pharmacodynamics of a new thromboxane synthetase inhibitor, 6-(1-Imidazolylmethyl)-5,6,7,8-tetrahydronaphthalene-2-carboxylic acid (DP-1904) in man after repeated oral doses. J. Pharm. Pharmacol., 42: 491-495 (1989).

9) Nagashima, R., O'Reilly, R.A. and Levy, G.: Kinetics of pharmacologic effects in man: The anticoagulant action of warfarin. Clin. Pharmacol. Ther., 10: 22-35 (1969).

10) Barrett, J. S., Gould, R. J., Ellis, J. D., Holahan, M. M., Stranieri, M. T., Lynch, J. J., Hartman, Jr. G. D., Ihle, N., Duggan, M., Moreno, O. A. and Theoharides, A. D.: Pharmacokinetics and pharmacodynamics of $\mathrm{L}-703,014$, a potent fibrinogen receptor antagonist, after intravenous and oral administration in dog. Pharm. Res., 11:426-431 (1994).

11) Averbuch, M., Weingraub, M., Liao, J.C., Brazzell, R.K. and Dobbs, R.E.: Red blood 
cell sorbitol lowering effects and tolerance of single doses of AL 1576 (HOE 843) in diabetic patients. J. Clin. Pharmacol., 28: 757-861 (1988).

12) Yamaoka, K., Tanagawa, Y., Nakagawa, T. and Uno, T.: A pharmacokinetic analysis program (MULTI) for microcomputer. J. Pharmacobio-Dyn., 4: 879-885 (1981).

13) Sato, H.: Pharmaceutical Research and Development (2nd Ser.), Tanaka, H. and Yamaoka, K. ed., Hirokawa Publishing Co., Tokyo, 1991; 39-65.

14) Grass, G. M. and Lee, V. H. L.: A model to predict aqueous humor and plasma pharmacokinetics of ocularly applied drugs. Invest. Ophthalmol. Vis. Sci., 34: 2251-2259 (1993).

15) Ramsay, M., Vallner,J. J. and Grass, G. M.: Pharmacokinetic simulations using Stella: Prediction of in vivo performance of oral dosage forms. Eur. J. Pharm. Biopharm., 37: 192-197 (1991).

16) Dayneka, N. L., Garg, V. and Jusko, W. J.: Comparison of four basic models of indirect pharmacodynamic responses. J. Pharmacokinet. Biopharm., 21: 457-478 (1993).

17) Zheng, N.X., Sato, H., Adachi, I. and Horikoshi, I.: Phamacokinetic and pharmacodynamic modeling of a thromboxane synthetase inhibitor, ozagrel, in human. Japan J. Hosp. Pharm., in press (1996).

18) Moskowitz, M.A. and Coughlin, S.R.: Basic properties of the prostaglandins. Stroke, 12: 696-701 (1981).

Appendix 1. Equations for a PK/PD Model Described in Fig. 3.

Submodel A:

$\mathrm{A}=0.000774^{*}$ dose

$\mathrm{B}=0.0333 *$ dose

$\mathrm{Cp}=$ if TIME $>=$ lag time then $\mathrm{A}^{*}\left(1-\operatorname{EXP}\left(-\mathrm{n}^{*}\right.\right.$ alpha*tau $\left.)\right) /(1-\operatorname{EXP}(-$ alpha*tau $)) * \operatorname{EXP}(-$ alpha*t' $)+\mathrm{B}^{*}(1-\operatorname{EXP}(-$ $\mathrm{n}^{*}$ beta $^{*}$ tau $\left.)\right) /(1-\operatorname{EXP}(-$ beta*tau $)) * \operatorname{EXP}\left(-\right.$ beta $\left.^{*} \mathrm{t}^{\prime}\right)-(\mathrm{A}+\mathrm{B}) *\left(1-\operatorname{EXP}\left(-\mathrm{n}^{*}\right.\right.$ gamma ${ }^{*}$ tau $\left.)\right) /(1-\operatorname{EXP}(-$ gamma*tau $))$

${ }^{*} \operatorname{EXP}(-$ gamma*t') else 0.00001

$\mathrm{n}=\operatorname{INT}(($ TIME-lag time $) / \mathrm{tau})+1$

$\mathrm{t}^{\prime}=$ TIME $-(\mathrm{n}-1) *$ tau-lag time

Submodel B:

TXB2 $(\mathrm{t})=\mathrm{TXB} 2(\mathrm{t}-\mathrm{dt})+($ Synthesis - Degradation_ $) * \mathrm{dt}$

INIT TXB2 $=100$

INFLOWS:

Synthesis $=$ Rsyn $0-$ Emax $^{*} \mathrm{Cp} \_/\left(\mathrm{EC} 50+\mathrm{Cp}_{-}\right)$

OUTFLOWS:

Degradation $=\mathrm{kd} * \mathrm{TXB} 2$

$\operatorname{Rsyn} 0=100^{*} \mathrm{kd}$ 